\title{
The Landscape Design of Sejong Center Square by applying the Combination of Geometric Lines
}

\author{
Jeong-Seob Jeong, Young-Rok Hong, Sang-Zoon Kwon, \\ Byung-Cheul Shin* and Yeon-Chul Choi**
}

\author{
Dept. of Environmental Landscape Architecture, Chongiu University, Chungbuk 360-764, Korea \\ 'Dept. of Environmental Landscape Architecture, Joongbu University, Chungnam 312-702, Korea \\ "Environmental Design L'Arte Inc., Seoul 135-841, Korea
}

(Manuscript received 24 December, 2002 ; accepted 30 January, 2003)

\begin{abstract}
This landscape design is a work for which we selected the square of Sejong Center for the Performing Arts as a object area, drew inhuman factors, and tried to restore them to human environment.

This plan assumes that excessive urban environment results from disorder and man can keep it in order and restore it to human environment through the progressive process of speculation. In this plan, we included the least parking space and nearby roads in the object area to maximize the location feature and the symbol of cultural space, and planned that the object area may play its role of open space in the downtown. To grant the symbol of culture space, we established the progressive process of speculation and the relationship of man, heaven and earth, and culture, geometrically diagrammatized it, combined the circular and rectangular lines derived from it, and suggested a plan.

Urban environment will continue to change in the future. However, as long as it is not ensured that the change will progress upward, city would be far from human environment anyhow. Efforts to display inhuman space overlooked in the downtown and restore it to human environment for citizen and location for man, should continue.
\end{abstract}

Key words : Human environment, Progressive process of speculation, Symbolic formation

\section{Introduction}

Science has changed human environment rapidly from only a few centuries ago, and influenced on modern civilization anyhow. Science accelerated urbanization and subsequent change of environment came to mean the process that ideal is realized. But we should not overlook that "realization of ideal is never going toward the progressive side of human environment and that modern civilization do not ensure human environment absolutely, for the change of urban environment provides the inhuman side of environment in inverse proportion to nature. In

Corresponding Author ; Jeong-Seob Jeong, Dept. of Environmental Landscape Architecture, Chongju University, Chungbuk 360-764, Korea

Phone : +82-43-229-8509

E-mail : aromacorea@empal.com accordance with this social background, 'The Neulpuleun Foundation' and 'Korea Institute of Landscape Architecture' held 'The 2nd Neulpuleun Environment Design Competition' on the subject of "restoration" in 2001. The subject means the declaration of new paradigm for inhuman reality resulting from science civilization, for it is a natural fact the present is on the continuous line of the past and the future until new paradigm is found.

Accordingly in this landscape design, we tried to secure space for human in the downtown and restore to human environment through the solutions of these problems.

\section{Analysis of Design Condition}

\subsection{Selection \& Feature of Object Area \\ For the object of detailed design on the}


subject of Competition, the following was suggested: (1) unused small area in the existing constructed space such as small park and remnant lot, (2) facilities through improvement of the wall in the concrete woods left from urbanization or use of a wall and vertical factors, (3) environment design centering on establishment, (4) Temporary Garden for urban environment through temporary event or establishment such as urban feast.

This work is applied for on the subject of the first of these. We selected the square of Sejong Center for the Performing Arts as the object area and designed for it. The square of Sejong Center for the Performing Arts located at Sejong-ro, Jongro-gu, Seoul was made up as a citizen square by the plan of Sejong Center for the Performing Arts public constructions in 1976(Fig. 1). The nearby area is for commercial and the square is surrounded by high storied buildings of over $40 \mathrm{~m}$ with complex facilities. Total area of the object is about

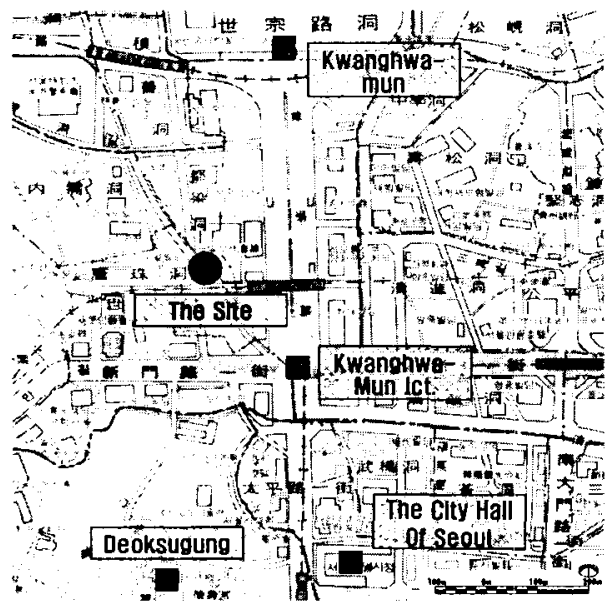

Fig. 1. A map on the location.

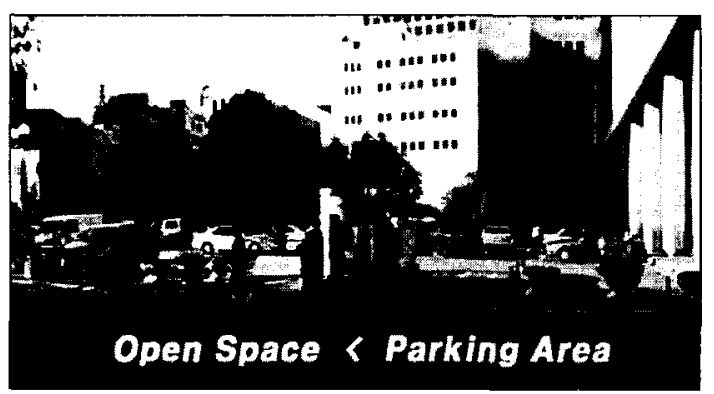

Fig. 3. Problems(I); Narrow space distribution.
$5,500 \mathrm{~m}^{2}$. Square facilities are about $1,100 \mathrm{~m}^{2}$ (1/5 of total area) and all the rest area is used as parking lot. Facilities using square are insufficient except for the rectangular waterscape facilities and pergola(Fig. 2).

\subsection{Suggestion of Problems}

The object area has location feature as a square attached to a construction(culture facilities) and does not play a role of open space accompanied with various activities such as rest in the downtown, meeting, assembly, etc.

In this work, we divided inhuman factors in the object area into three.

(1) Most square is used as parking facilities and presents narrow space distribution. Consequently, the object area is surrounded by the cover of parking facilities and the fence for a boundary to be closed space(Fig. 3).

(2) The square surrounded by parking facilities is not secured open space, so its location feature as cultural space is overlooked(Fig. 4).

(3) In addition, excess of parking space results in vehicle-centered selfish moving line system. When entering into a construction, people is bounded to pass parking facilities because there is no separate sidewalk(Fig. 5).

Therefore we may conclude the object area

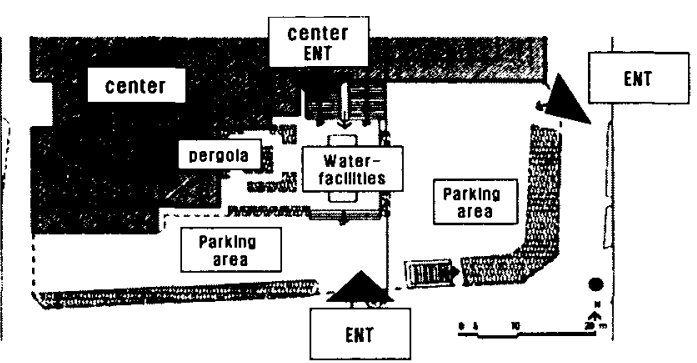

Fig. 2. A map of the present condition.

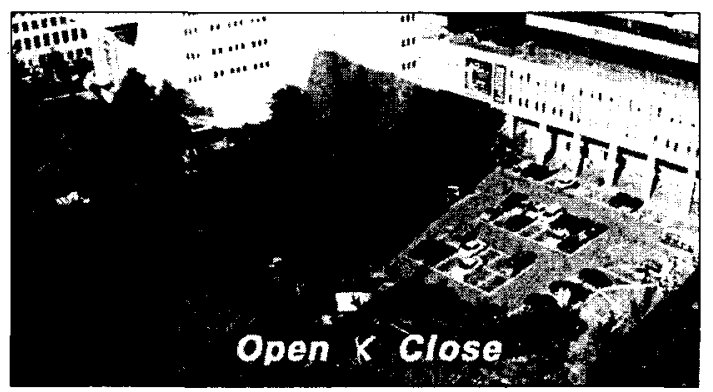

Fig. 4. Problems(II); Location feature as cultural space is overlooked. 
is a inhuman space of disharmony between interspace laking of unity and of narrowness and selfishness not holding the symbol of culture.

\subsection{Solutions}

Inhuman factors of this object area results from disorder due to excessive urban environment and it means the process of downward retrogression of culture. Therefore the location feature for the upward progress of culture should be secured, for it, square facilities except for the least parking space should be an emblem of order, as a space for the symbol of culture and human environment. To maximize narrow square facilities, we removed existing fence and cover and coordinated the pavement pattern with nearby roads, that is, we tried to solve the problems of this object area by securing open space as culture space with unity of space and order system of moving line(Fig. 6).

\section{Design concept}

\subsection{Concept of Human Environment}

Disorder is downward retrogression of culture and the start of inhuman environment. This plan assumes that excessive urban environment results from disorder and is based on the abstract concept that culture progresses upward and human environment develops by keeping it in order.

Disorder is the product of downward retrogression of culture, excessive urban environment is the result of continuing disorder, and it means loss of self-purification. Man is united with heaven and earth by the principle of

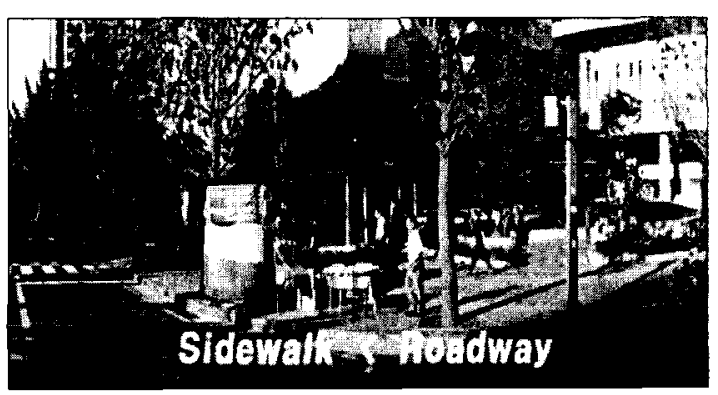

Fig. 5. Problems(II); Vehicle-centered selfish moving line system. nature, and Nature as complete order system is the basis of human environment. Accordingly human environment means aggregate concept of things based on order between heaven and earth. Based on this, man improves the possibility of upward progress of culture through progressive speculation process. Culture as the whole of symbolic and creative shapes is an emblem of desire for man's order. Culture is the process of opening the door of order, and human environment and upward progress of culture form the interactive system.

\subsection{Concept of Plan}

Concept of this plan begins from suggestion of the problem, 'How can we restore inhuman factors in the downtown to human environment?'

\subsubsection{Concept of Human Environmental}

This plan assumes that factors of inhumanization result from disorder and that human environment can be restored by keeping them in order. Being ordered means man's speculative progress, and the speculative progress begins at the process of defining the bipolar concepts such as positive and negative, movement and stillness, existence and nonexistence, etc. and contrasting them. Through the bipolar contrasting process, we defined the starting point of being ordered as the door between the two poles and defined the process of being ordered, that is, the abstract speculation process as a stationary wave. Also, one polar is a circle and a combination of these two poles is

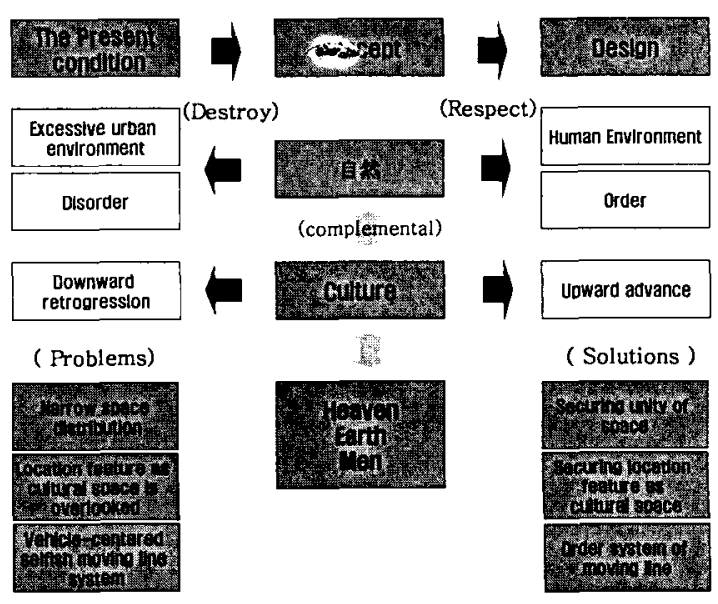

Fig. 6. A development process of plan. 
ordered entity. The progressive process of being ordered is explained as a combined circle of one combination of two poles and another combination of two poles. In here, the space between door and door means time space and explains indirectly that the universe should be the premise of man' cognition(Fig. 7).

\subsubsection{Concept of Heaven, Earth, and Man}

The gist of conceptual framework introduced the relationship of generation and extinction. At the point of generation, disorder is shaped into rock, it is diluted with a flow of time and the progress of speculation process, and finally is extinguished at the extreme point. The extinction point consists of water and it is another creative generation point and the starting point

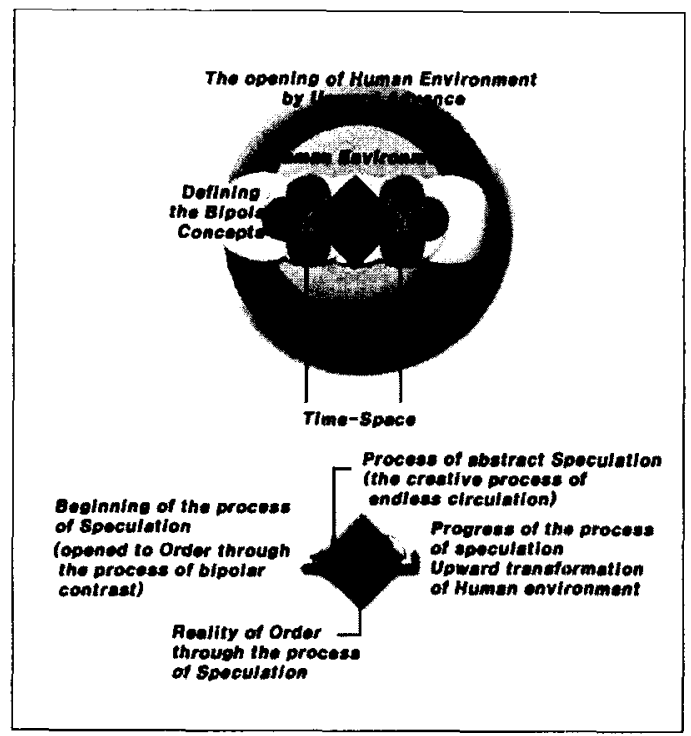

Fig. 7. Concept of Human Environmental.

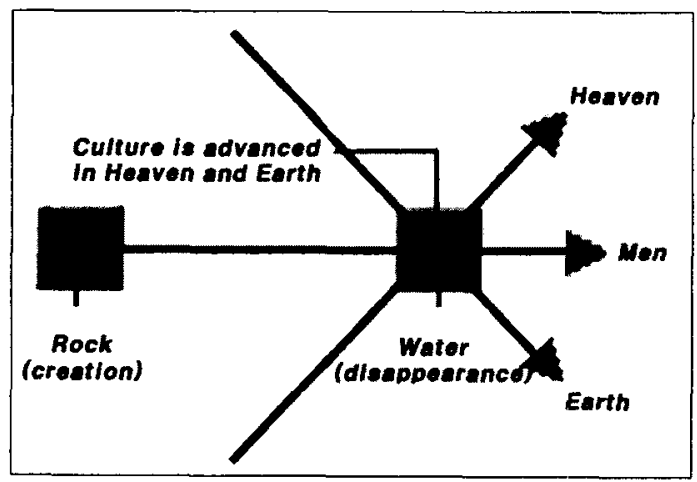

Fig. 8. Concept of Heaven, Earth, and Man. of culture. Culture is the process of accomplishing man's will in heaven and earth, and three axes meaning heaven, earth, and man is established(Fig. 8).

\subsubsection{Concept of Culture}

This plan assumes water to be the principle of nature and established the relationship that heaven, earth and man form culture, respecting one another. The point three axes of heaven, earth, and man meet is based on the extinction point and again it becomes the creation point of culture(Fig. 9).

\section{Design study}

This plan was drawn using combination of circular and rectangular geometric lines derived from concept(Fig. 10; Fig. 11).

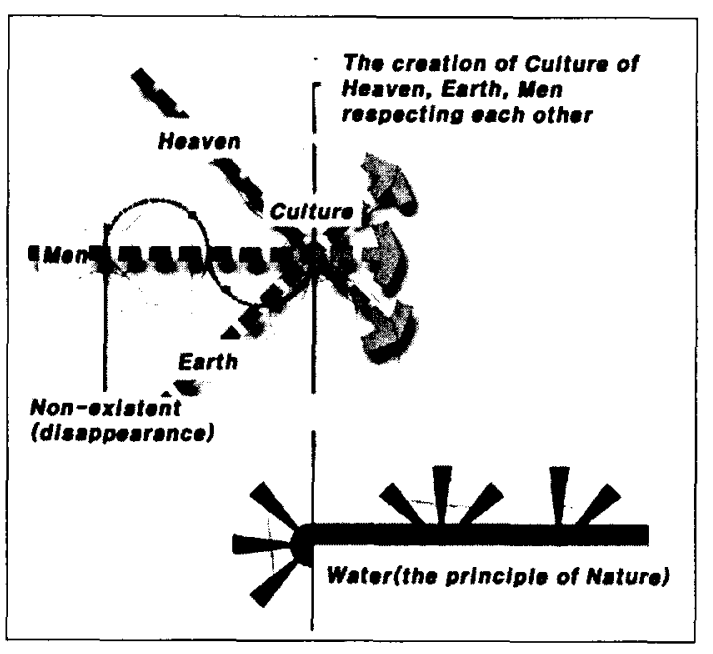

Fig. 9. Concept of Culture.

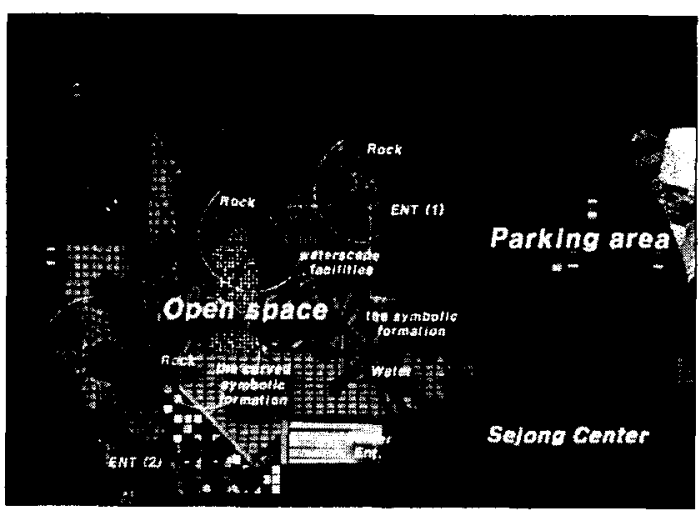

Fig. 10. Master plan. 
the Combination of Geometric Lines

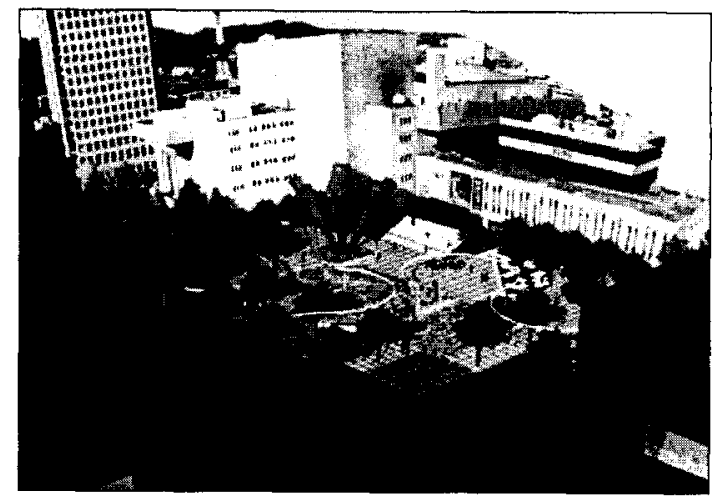

Fig. 11. Perspective.

Circle meaning human environment includes nearby roads, and paving materials and pattern are identical. That is, location feature as cultural space for temporary event or assembly is secured to the maximum. In the square, the shape of curved formations and rectangular waterscape facilities make a plane contrast, and a symbolic formation is located at the joining point of circular line and rectangular line. Trees are planted in line to accent at the entry and are planted a different kind of trees to differentiate from street trees. For the symbolic formation of the center, the entry of a formation and the entry of a square(1) form the principal axes and three inverse triangular pyramids meaning heaven, earth, and man are based on water. Again three pyramids are combined on the subaxes of the base and the entry of a square(2). In here, because man is the center and overlapped, the symbolic formation consists of five posts in total. The curved symbolic formation is about $2.3-2.7 \mathrm{~m}$ high and the curved line of a formation is viewed with waterscape facilities at the entry(about $6.5 \mathrm{~m}$ ) of it.

Thus, we suggested the plan as the solutions for inhuman factors of the object area. The concrete figure of restoration is as follows:

\subsection{Securing Unity of Space}

For parking lot, it is premised that all vehicles except facilities vehicles use an underground parking lot. The entry(1) becomes the boundary of parking lot and open space, and trees in line function as cover as well as accent. That is, square facilities form a perfect square bounded by trees of the entry(1) and the entry(2), so divided from parking facilities. In addition, the same paving materials and pattern are used for unity of space.

\subsection{Securing Location Feature as Cultural Space}

Cover and boundary fence surrounding the square are removed and existing trees are transplanted to the entry(1) to expand open space into nearby roads and secure the location feature as cultural space.

\subsection{Order System of Sidewalk and Road Way Moving Line}

Vehicle-centered moving line is strictly divided from side walks with reduction of parking facilities. In the square, the symbolic formation and waterscape facilities constitute the frame of moving line and certain moving line does not exist.

\section{References}

1) Amidon, J., 2001, Radical Landscapes, Thames \& Hudson.

2) BDLA, 2002, Neu verorten Making Spaces, Birkhäuser.

3) Kasiske, M., and T. Schröder, 2001, Garden Art 2001, Birkhäuser

4) Wolch, J. K. and West \& T. Gaines, 1995. Transspecies Urban Theory, Environment \& Planning D : Society and Space, 13(6), 735760.

5) Song, M. K., 1994, The Development of Environmental Philosophy(1) : Environmental Ethics. Journal of The Korean Regional Development Association, 19(2), 79-109.

6) Lim, K. W., 2000, A Study on the EcoOriented View of Nature for Establishment of an Environmental Philosophy. Journal of The Korean Regional Development Association, 25(2), 227-242. 